Original Research Article

\title{
Study of drug utilization in cardiovascular emergency at a rural teaching hospital in Tamilnadu, India
}

\author{
Mohammed Fardan ${ }^{1 *}$, S. Manjari ${ }^{1}$, S. Periasamy ${ }^{2}$
}

${ }^{1}$ Department of Pharmacy, Annamalai University, Chidambaram, Tamil Nadu, India

${ }^{2}$ Department of Medicine, Rajah Muthiah Medical College Hospital, Chidambaram, Tamil Nadu, India

Received: 22 April 2019 Accepted: 30 May 2019

*Correspondence to: Mohammed Fardan, Email: mohammedfardan4@ gmail.com

Copyright: (C) the author(s), publisher and licensee Medip Academy. This is an openaccess article distributed under the terms of the Creative Commons Attribution NonCommercial License, which permits unrestricted noncommercial use, distribution, and reproduction in any medium, provided the original work is properly cited.

\begin{abstract}
Background: Cardiovascular disease is a common term which encompasses a range of disorders that affect the heart. Cardiovascular disease is the leading cause of death among men and women in India and across the globe. There is evidence of irrational drug use in cardiovascular disorders. Drug utilization study is used to evaluate the rationality of medication use. The objective of this study was to observe the most frequently treated emergency cardiovascular diseases and to study the prescribing pattern among inpatients admitted in CICU Unit of tertiary care teaching hospital.
\end{abstract}

Methods: A retrospective, observational drug utilization study was designed to evaluate the drug prescribing pattern in cardiovascular emergency patients admitted in CICU unit of tertiary care teaching hospital. Study was carried out for a duration of 4 months. Data were collected from patient case reports after getting permission from Medical superintendent of hospital. Prescribing pattern of drugs were studied based on WHO indicators.

Results: Total 150 patients were included in the study. Most common cardiovascular emergency reported was Myocardial infarction $(60.66 \%)$ followed by Angina pectoris $(24.66 \%)$. The most common comorbidities found along with cardiovascular emergency were hypertension $(62.66 \%)$ followed by Diabetes mellitus (15.33\%). Most prescribed cardiovascular drugs were from the category of hypolipidemics $(94.66 \%)$ and anti-platelets $(92.66 \%)$. Average number of drugs per prescription was found to be 9.42 . Average hospital stay per patient was found to be 4.25 days. Percentage of drugs prescribed by generic name was $70.66 \%$. Percentage of drugs prescribed from essential drug list and National list of essential medicines were $87.4 \%$ and $97.23 \%$ respectively.

Conclusions: All the drugs prescribed were according to the current guidelines. Majority of the drugs were prescribed in generic form.

Keywords: Cardiovascular emergency, Drug utilization study, Generic drugs, Prescription auditing

\section{INTRODUCTION}

Cardiovascular diseases (CVDs) end the lives of 17.9 million individuals consistently, $31 \%$ of all worldwide deaths; setting off these diseases which show basically as heart attacks and strokes include tobacco use, unfortunate eating regimen, physical inactivity and the hurtful utilization of liquor; these thus appear in individuals as raised blood pressure, hoisted blood glucose, overweight and obesity, risks detrimental to cardiac wellbeing. ${ }^{1}$

The Indian subcontinent also experiences a huge loss of productive working years due to CVD demise. 
Drug utilization study is used to evaluate the rationality of medication usage. It gives a positive input to prescribing physicians and help them to alter treatment strategies whenever necessary, identify, and right the weaknesses assuming any, hence giving the patients a rational and cost-effective treatment. Attributable to defencelessness of patient with CVDs to different complications, drug interactions and adverse events, these study tools are must in every hospital.

Prescription pattern is necessary, as it plays an important role in conveying message from prescriber to a patient. The use of least number of drugs to obtain best possible effect in the shortest period and that too at reasonable cost will be highly appreciable to achieve so called rationality in prescription. $^{2}$ Inappropriate use of medicines, development of resistance and economic burden on patients and the society are the consequences of irrationality.

The objective of this study was to observe the most frequently treated emergency cardiovascular diseases and to study the prescribing prevalence among inpatients admitted in CICU Unit of the hospital, using WHO drug indicators.

\section{METHODS}

It was a retrospective observational study to evaluate the drug prescribing pattern in cardiovascular emergency patients admitted to CICU of a tertiary care teaching hospital of south India. Study was carried out for a duration of 4 months (September 2018- December 2018).

\section{Inclusion criteria}

Data of patients diagnosed with CVDs and admitted to the CICU were included in the study.

\section{Exclusion criteria}

Incomplete case records and patients referred or discharged from hospital $<24 \mathrm{hrs}$ were excluded.

\section{Study procedure}

Using the 150 medical records data's like demographic details (age and sex), cardiovascular emergency, diagnosis and prescription details, average duration of stay in the hospital, outcome of the patient, number of drugs/prescriptions, percentage of drugs prescribed by generic name and percentage of drugs which are included in the essential drug list were collected. Data were collected by PharmD interns. Data were recorded as per WHO guidelines.

\section{Statistical analysis}

Data were analysed as per WHO guidelines given in WHO manual "How to investigate drug use in health facilities".
The information extracted was entered in Microsoft Excel sheet. Demographic data were analysed in the form of percentage and average.

\section{RESULTS}

Authors have analysed data of 150 patients. Out of 150 patients, $93(62 \%)$ were males and $57(38 \%)$ were females (Figure 1), which indicates that cardiovascular emergency was more in male when compared to female. Myocardial infraction and Angina pectoris are the two groups of Ischemic heart disease. ${ }^{3}$ Table 1 indicates that common cardiovascular emergency was MI (60.66\%), Angina pectoris $(24.66 \%)$ followed by CCF (13.33\%) and Arrhythmia (1.33\%). Gender wise distribution based on diseases is shown in Table 2.

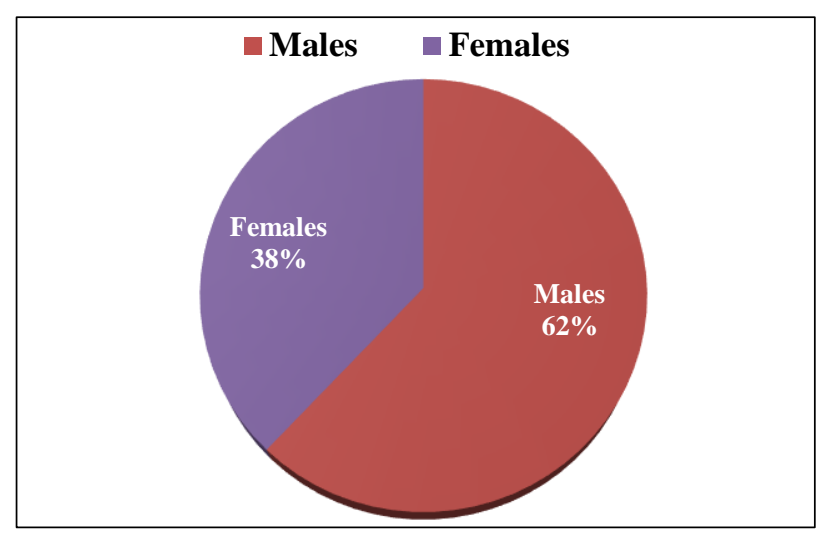

Figure 1: Gender wise distribution of cardiovascular emergencies in this study.

Table 1: Most common cardiovascular emergencies reported in this study.

\begin{tabular}{|lll|}
\hline $\begin{array}{l}\text { Cardiovascular } \\
\text { emergencies }\end{array}$ & $\begin{array}{l}\text { No. of } \\
\text { patients }\end{array}$ & Percentage \\
\hline MI & 91 & $60.66 \%$ \\
\hline Angina pectoris & 37 & $24.66 \%$ \\
\hline Arrhythmias & 2 & $1.33 \%$ \\
\hline CCF & 20 & $13.33 \%$ \\
\hline Total & 150 & $100 \%$ \\
\hline
\end{tabular}

MI: Myocardial Infarction, CCF: Congestive Cardiac Failure

Table 2: Gender wise distribution based on diseases.

\begin{tabular}{|c|c|c|c|}
\hline \multirow{2}{*}{$\begin{array}{l}\text { Cardiovascular } \\
\text { emergencies }\end{array}$} & \multirow{2}{*}{ Total } & \multicolumn{2}{|l|}{ Gender } \\
\hline & & Male & Female \\
\hline MI & 91 & $\begin{array}{l}56 \\
(37.33 \%)\end{array}$ & $35(23.33 \%)$ \\
\hline Angina pectoris & 37 & $\begin{array}{l}23 \\
(15.33 \%)\end{array}$ & $14(9.33 \%)$ \\
\hline Arrhythmias & 2 & $2(1.33 \%)$ & 0 \\
\hline $\mathrm{CCF}$ & 20 & $12(8 \%)$ & $8(5.33)$ \\
\hline Total & 150 & $93(62 \%)$ & $57(38 \%)$ \\
\hline
\end{tabular}




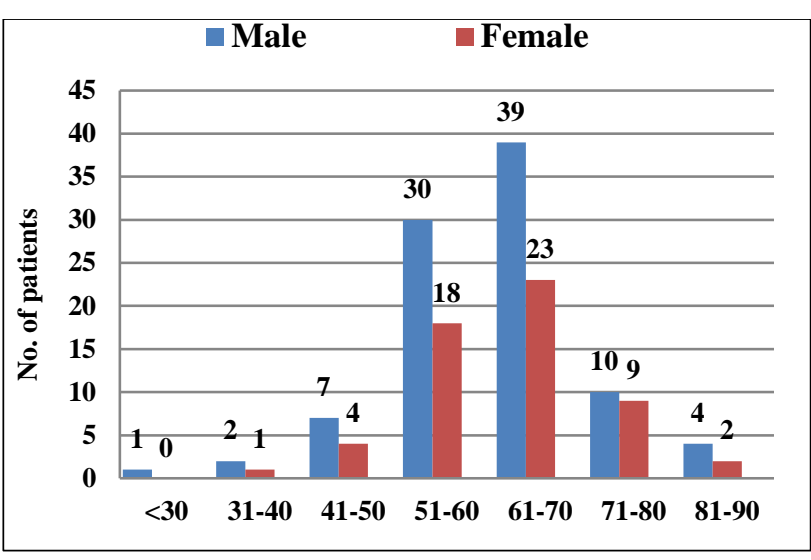

Figure 2: Age-wise distribution of male and female patients.

Table 3: Association of other comorbidities with the cardiovascular emergencies reported in our study.

\begin{tabular}{|c|c|c|}
\hline Comorbidities & No. of patients & Percentage \\
\hline HTN & 94 & 62.66 \\
\hline Dyslipidemia & 5 & 3.33 \\
\hline DM & 23 & 15.33 \\
\hline CVA & 2 & 1.33 \\
\hline Gastritis & 1 & 0.66 \\
\hline Hypothyroidism & 4 & 2.66 \\
\hline Anemia & 3 & 2.0 \\
\hline COPD & 1 & 0.66 \\
\hline $\begin{array}{l}\text { Acute pulmonary } \\
\text { edema }\end{array}$ & 2 & 1.33 \\
\hline CKD & 5 & 3.33 \\
\hline Asthma & 3 & 2.0 \\
\hline Seizures & 4 & 2.66 \\
\hline TB & 2 & 1.33 \\
\hline Fibroid uterus & 1 & 0.66 \\
\hline $\begin{array}{l}\text { HTN: Hypertension } \\
\text { Cerebrovascular ac } \\
\text { Pulmonary Disease, } \\
\text { Tuberculosis }\end{array}$ & \begin{tabular}{ll} 
DM: & \multicolumn{2}{c}{ Diabetes } \\
ent, & COPD: \\
KD: & Chronic \\
\end{tabular} & $\begin{array}{l}\text { Mellitus, C } \\
\text { onic Obstruc } \\
\text { hey Disease, }\end{array}$ \\
\hline
\end{tabular}

Figure 2 shows the age wise distribution of male and female patients, in which incidence of cardiovascular emergency was found to be more in the age group of 5170 years in both the genders and was significantly low in age group of 31-50 years.

Table 3 shows the association of other comorbidities with the cardiovascular emergencies in our study, Hypertension and diabetes mellitus were the most commonly found comorbidity.

Hypolipidaemic $142(94.66 \%)$ and antiplatelets 139 $(92.66 \%)$ were the most common classes of cardiovascular drugs prescribed followed by anticoagulants $80(53.33 \%)$ as shown in Table 4 and 5.

Out of 91 patients diagnosed with MI 50 patients had STEMI. Streptokinase and reteplase were the fibrinolytics used. Intravenous furosemide was the most commonly used diuretic followed by spirinolactone. Inotropes like Dopamine, dobutamine and noradrenaline were used more commonly (Table 5).

\section{Table 4: Various classes of cardiovascular} drugs prescribed.

\begin{tabular}{|lll|}
\hline Drug class & No. of prescriptions & Percentage \\
\hline Beta Blocker & 36 & 24 \\
\hline ACE Inhibitors & 27 & 18 \\
\hline ARB's & 14 & 9.33 \\
\hline Diuretics & 59 & 39.33 \\
\hline Anti-platelet & 139 & 92.66 \\
\hline Anti-coagulant & 80 & 53.33 \\
\hline Fibrinolytics & 27 & 18 \\
\hline Hypolipidemic & 142 & 94.66 \\
\hline $\begin{array}{l}\text { Calcium } \\
\text { channel } \\
\text { blockers }\end{array}$ & 21 & 14 \\
\hline Anti-anginals & 26 & 17.33 \\
\hline $\begin{array}{l}\text { Cardiac } \\
\text { glycosides }\end{array}$ & 7 & 4.66 \\
\hline Anti-arrhythmia & 2 & 1.33 \\
\hline Inotropes & 15 & 10 \\
\hline Vasodilator & 2 & 1.33 \\
\hline $\begin{array}{l}\text { ACE: Angiotensin } \\
\text { Receptor blocker }\end{array}$ & Converting Enzyme, ARB: Angiotensin \\
\hline
\end{tabular}

Improvement was seen in $123(82 \%)$, while discharge at medical request was seen in $24(16 \%)$ as shown in Table 6.

Table 7 shows the ATC/DDD classification and utilization rate of drugs. DDDs mentioned here in the table is obtained from WHO ATC/DDD website. This study shows that; Atorvastatin, ivabradine, ramipril, enalapril, furosemide is over utilised, since the PDD/DDD ratio is greater than 1.

Comparably Metoprolol, carvedilol, Telmisartan, spironolactone, warfarin, Amlodipine, cilnidipine, isosorbide di nitrate, ranolazine, dobutamine, noradrenaline is all under-utilised since PDD/DDD ratio being less than 1. Drugs which showed PDD/DDD ratio equal to 1 complying with the WHO ATC/DDD index include streptokinase, rosuvastatin, aspirin, clopidogrel and digoxin.

Table 8 depicts the analysis of prescription pattern according to drug use indicators. $70.66 \%$ of drugs were prescribed in generic name, $29.33 \%$ were prescribed by brand name, $30.46 \%$ prescriptions were seen to contain injections, Average number of drugs per prescription was seen to be 9.42 . $18.66 \%$ of prescription contained antibiotics. Average duration of hospital stay per patient was studied as 4.25 days. $87.4 \%$ of drugs prescribed were from Essential Drug list (EDL) 2016-2018. 97.23\% of drugs prescribed were from national list of essential medicines (NLEM) 2015. 
Table 5: Pattern of drugs utilized in patients with cardiovascular emergencies.

\begin{tabular}{|c|c|c|c|}
\hline Drug class & Drug name (generic name) & Number of prescriptions & Percentage of prescription (\%) \\
\hline \multirow{4}{*}{ Beta-blocker } & Atenolol & 1 & 2.77 \\
\hline & Metoprolol & 29 & 80.55 \\
\hline & Carvedilol & 4 & 11.11 \\
\hline & Bisoprolol & 2 & 5.55 \\
\hline \multirow{2}{*}{ ACE Inhibitors } & Ramipril & 4 & 16.66 \\
\hline & Enalapril & 23 & 85.15 \\
\hline \multirow{2}{*}{ ARB } & Losartan & 3 & 21.42 \\
\hline & Telmisartan & 11 & 78.57 \\
\hline \multirow{4}{*}{ Diuretics } & Furosemide & 48 & 81.35 \\
\hline & Spironolactone & 7 & 11.86 \\
\hline & Metolazone & 1 & 1.69 \\
\hline & Hydrochlorothiazide & 3 & 5.08 \\
\hline \multirow{4}{*}{ Anti-platelet } & Aspirin & 32 & 23.02 \\
\hline & Clopidogrel & 7 & 5.03 \\
\hline & Clopidogrel A & 98 & 70.50 \\
\hline & Ticagrelor & 2 & 1.43 \\
\hline \multirow{4}{*}{ Anti-coagulant } & Enoxaparin & 48 & 60 \\
\hline & Warfarin & 25 & 31.25 \\
\hline & Acenocoumarol & 4 & 5 \\
\hline & Fondaparinux & 3 & 3.75 \\
\hline \multirow{2}{*}{ Fibrinolytics } & Streptokinase & 25 & 92.5 \\
\hline & Reteplase & 2 & 7.40 \\
\hline \multirow{2}{*}{ Hypolipidemics } & Atorvastatin & 138 & 97.18 \\
\hline & Rosuvastatin & 4 & 2.8 \\
\hline \multirow{2}{*}{$\begin{array}{l}\text { Calcium channel } \\
\text { blocker }\end{array}$} & Amlodipine & 19 & 90.47 \\
\hline & Cilnidipine & 2 & 9.52 \\
\hline \multirow{6}{*}{ Anti-anginals } & Nitroglycerin & 15 & 57.69 \\
\hline & Ivabradine & 4 & 15.38 \\
\hline & Isosorbide di nitrate & 3 & 11.53 \\
\hline & Ranolazine & 1 & 3.84 \\
\hline & Trimetazidine & 1 & 3.84 \\
\hline & Nicorandril & 2 & 7.69 \\
\hline Cardiac glycosides & Digoxin & 7 & 100 \\
\hline Anti-arrhythmics & Amiodarone & 2 & 100 \\
\hline \multirow{3}{*}{ Inotropes } & Dopamine & 4 & 26.66 \\
\hline & Dobutamine & 6 & 40 \\
\hline & Noradrenaline & 5 & 33.33 \\
\hline Vasodilator & Hydralazine & 2 & 100 \\
\hline
\end{tabular}

ACE: Angiotensin converting enzyme, ARB: Angiotensin receptor blocker

Table 6: Outcome of Cardiovascular emergency patients treated in this study.

\begin{tabular}{|lllll|}
\hline Cardiovascular emergencies & Total & Outcome & Death & DAMA \\
\hline MI & 91 & Discharge & 1 & 5 \\
\hline Angina pectoris & 37 & 25 & 0 & 12 \\
\hline Arrhythmias & 2 & 2 & 0 & 0 \\
\hline CCF & 20 & 11 & 2 & 7 \\
\hline Total & 150 & $123(82 \%)$ & $3(2 \%)$ & $24(16 \%)$ \\
\hline
\end{tabular}

MI: - Myocardial infarction, CCF: - Congestive cardiac failure

\section{DISCUSSION}

Drug utilization study is utmost important in different health care setups to analyse the behaviour of use of medicines by the society and to impart safe health care. Inappropriate use of medicines, development of resistance and economic burden on patients and the society are the consequences of irrationality. 
Table 7: PDD/DDD ratio of cardiovascular emergency drugs used.

\begin{tabular}{|lllll|}
\hline Drug & ATC code & PDD & DDD & PDD/DDD \\
\hline Atorvastatin & C10AA05 & $25.70 \mathrm{mg}$ & $20 \mathrm{mg}$ & 1.285 \\
\hline Rosuvastatin & C10AA07 & $70 \mathrm{mg}$ & $10 \mathrm{mg}$ & 7 \\
\hline Amlodipine & C08CA01 & $3.42 \mathrm{mg}$ & $5 \mathrm{mg}$ & 0.684 \\
\hline Cilnidipine & C08CA14 & $5 \mathrm{mg}$ & $10 \mathrm{mg}$ & 0.5 \\
\hline Isosorbide di nitrate & C01DA08 & $10 \mathrm{mg}$ (sublingual) & $20 \mathrm{mg}$ (sublingual) & 0.5 \\
\hline Ranolazine & C01EB18 & $1 \mathrm{~g}$ & $1.5 \mathrm{~g}$ & 0.666 \\
\hline Ivabradine & C01EB17 & $15 \mathrm{mg}$ & $10 \mathrm{mg}$ & 1.5 \\
\hline Aspirin & B01AC06 & 1 tablet & 1 tablet & 1 \\
\hline Clopidogrel & B01AC04 & $75 \mathrm{mg}$ & $75 \mathrm{mg}$ & 1 \\
\hline Digoxin & C01AA05 & $0.25 \mathrm{mg}$ & $0.25 \mathrm{mg}$ & 1 \\
\hline Amiodarone & C01BD01 & $0.2 \mathrm{~g}$ & $0.2 \mathrm{~g}$ & 1 \\
\hline Dobutamine & C01CA07 & $0.25 \mathrm{~g}$ & $0.5 \mathrm{~g}$ & 0.5 \\
\hline Noradrenaline & C01CA03 & $4 \mathrm{mg}$ & $6 \mathrm{mg}$ & 0.666 \\
\hline Metoprolol & C07AB02 & $0.05 \mathrm{~g}$ & $0.15 \mathrm{~g}$ & 0.333 \\
\hline Carvediol & C07AG02 & $25 \mathrm{mg}$ & $37.5 \mathrm{mg}$ & 0.666 \\
\hline Ramipril & C09AA05 & $5 \mathrm{mg}$ & $2.5 \mathrm{mg}$ & 2 \\
\hline Enalapril & C09AA02 & $17.82 \mathrm{mg}$ & $10 \mathrm{mg}$ & 1.782 \\
\hline Telmisartan & C09CA07 & $36.36 \mathrm{mg}$ & $40 \mathrm{mg}$ & 0.909 \\
\hline Furosemide & C03CA01 & $46.66 \mathrm{mg}$ & $40 \mathrm{mg}$ & 1.166 \\
\hline Spironolactone & C03DA01 & $50 \mathrm{mg}$ & $75 \mathrm{mg}$ & 0.666 \\
\hline Warfarin & B01AA03 & $3 \mathrm{mg}$ & $7.5 \mathrm{mg}$ & 0.4 \\
\hline Streptokinase & B01AD01 & $1.5 \mathrm{million}$ units & $1.5 \mathrm{million}$ units & 1 \\
\hline
\end{tabular}

ATC Code: Anatomical Therapeutic Chemical Classification Code, DDD: - Daily defined dose, PDD: Prescribed daily dose.

Table 8: WHO drug prescribing indicators.

\begin{tabular}{|ll|}
\hline Drug use indicators & Results \\
\hline \% of drugs prescribed by brand name & $29.33 \%$ \\
\hline$\%$ of drugs prescribed by generic name & $70.66 \%$ \\
\hline \% of prescriptions with an injection & $30.46 \%$ \\
\hline \% of prescriptions with antibiotics & $18.66 \%$ \\
\hline Average No. of drugs per prescription & 9.42 \\
\hline Average hospital stay per patient & 4.25 days \\
\hline $\begin{array}{l}\text { Number of drugs prescribed from } \\
\text { National List of Essential Medicines } \\
\text { (NLEM)- 2015 }\end{array}$ & $97.23 \%$ \\
\hline $\begin{array}{l}\text { Number of drugs prescribed from } \\
\text { Essential Drug List (EDL)- 2016-2018 }\end{array}$ & $87.40 \%$ \\
\hline
\end{tabular}

In the present study, out of $93(62 \%)$ male and $57(38 \%)$ female case sheets analysed; the incidence of cardiovascular emergency was most commonly found in the age group of 51-70 years in both the sexes suggesting that the elders are more prone to the cardiac events, which were in accordance with Kerkar SS et al. ${ }^{4}$ Here authors also found that incidence of cardiovascular diseases is higher in males than in females. After menopause oestrogen's protective effect on cardiac health declines, which could be a reason for increased incidence of cardiovascular disease in female patients, since in our study data shows females with age group 51-70 are affected the most.
Out of 91 MI cases, $56(61.53 \%)$ were male and 35 $(38.46 \%)$ were female. Most common comorbid conditions found in patients were hypertension 94 $(62.66 \%)$ and diabetes mellitus $23(15.33 \%)$, this observation was similar to those of $\mathrm{H}$. Nagabhushan et al, and Pendhari SR et al. ${ }^{5,6}$ Most common cardiovascular emergency was found to be MI $91(60.66 \%)$ followed by Angina pectoris 37 (24.66\%), which were in agreement with the study conducted by Vakade KP et al. ${ }^{7}$

Hypolipidemics 142 (94.66\%) and antiplatelets 139 (92.66\%) followed by anticoagulants $80(53.33 \%)$ were the most commonly prescribed drug classes. These results are in accordance with Kerkar SS et al, and Nagabhushan $\mathrm{H}$ et al. ${ }^{4,5}$ Apart from these; drug utilization rate of diuretics, beta blockers, ACE inhibitors were also seemed to be high.

Aspirin+Clopidogrel combination was the most common fixed dose combination antiplatelet drug present in prescriptions, this result is in agreement with the study done by Nooreen $\mathrm{M}$ et al. ${ }^{8}$ This dual combination therapy is recommended by ACC/AHA for the management of CAD. Atorvastatin was the commonest prescribed hypolipidemic agent, according to ACC/AHA guidelines and Atherosclerotic cardiovascular disease (ASCVD) Risk calculator, moderate to high intensity statin therapy should be used in persons aged 40 to 75 years without clinical ASCVD or diabetes but with an estimated 10-year 
ASCVD risk of $7.5 \%$ or greater, on the other hand if the 10 -year risk of ASCVD is less than 7.5\%, moderate intensity statin is equitable. ${ }^{9}$

Among ACE inhibitors, enalapril was the most use drug, furosemide was the most used diuretic agent, enoxaparin and warfarin were the agents among anticoagulants. Streptokinase was the most used fibrinolytic in our study centre. Amlodipine and nitroglycerin were the most used calcium channel blocker and anti-anginal respectively.

Dopamine was found to be the most used positive inotrope from our study followed by dobutamine and noradrenaline. This result is in accordance to the study done by Nagabushan $\mathrm{H}$ et al, and is contrast to the study conducted by Lavanya $\mathrm{S}$ et al, where adrenaline is the most frequently used positive inotrope followed by noradrenaline and dobutamine. ${ }^{5,10}$ This shows that there is a mark difference in the use of inotropes in patients with cardiovascular emergency.

Among non-cardiovascular drugs like Proton pump inhibitors, stool softeners, antiemetics, antacids and benzodiazepines were most commonly prescribed in our study.

Study conducted by Vakade KP et al, average stay in hospital was found to be 5.75 days, our study shows 4.25 as the average hospital stay. $70.66 \%$ of drugs were prescribed in generic form, $29.33 \%$ were prescribed in brand name, these results differ strikingly from the study conducted by Chandana $\mathrm{N}$ et al. ${ }^{11}$ This also reflects that free medicines offered in the government hospital located in rural areas are generic drugs, which is highly appreciable. Number of prescriptions with an injection were $30.46 \%$ which is in conformity with study conducted by Aswani $\mathrm{R}$ et al, (34.99\%) and much lower than the study by Kerkar SS et al. ${ }^{12,4}$ Advantage of parenteral drugs is their ability to enhance drug adherence, the data recorded above is important since parental medications add to the expense of the prescription, also majority of adverse effects occurs through this route of administration.

Motivation behind ATC/DDD framework is to fill in as an instrument for drug utilization studies and research so as to improve nature of drug using ACT/DDD system, categorises the drugs based upon their pharmacological and therapeutic properties. The DDD for each drug were taken from the WHO collaboration centre for drug statistics methodology ATC/DDD website. ${ }^{13}$ This concept applies that each individual who is endorsed a specific drug is taking the drug according to its respective DDD, overlooking the adjustment of the dosage for every illness and the patient related components. Prescribed daily dose (PDD) is defined as the average dose prescribed according to a representative sample of prescription. PDD will give the average daily amount of a drug that is actually prescribed.
Ratio of PDD and DDD is used to evaluate drug utilization data. If the ratio is less than 1 , it may indicate underutilisation of drug and if ratio is greater than 1 , then over utilization of the drug is inferred. This study shows that; Atorvastatin, ivabradine, ramipril, enalapril, furosemide is over utilised, since the PDD/DDD ratio is greater than 1. Comparably Metoprolol, carvedilol, Telmisartan, spironolactone, warfarin, Amlodipine, cilnidipine, isosorbide di nitrate, ranolazine, dobutamine, noradrenaline is all under-utilised since PDD/DDD ratio being less than 1. Drugs which showed PDD/DDD ratio equal to 1 complying with the WHO ATC/DDD index include streptokinase, rosuvastatin, aspirin, clopidogrel and digoxin. Study conducted by Hannan A et al, also showed somewhat similar results. ${ }^{14}$ Lot of discrepancies between prescribed and defined daily doses are seen. Nevertheless, it is imperative to take note of PDD that can fluctuate according to both the indicated diseases treated and national therapeutic practices. Also, the PDDs additionally change considerably between various nations, PDDs are regularly lower in Asian than in Caucasian populations. On account of this it might appear as though there is underutilisation or over utilization of specific drugs based on the requirement. ATC/DDD system by itself is not suitable for controlling choices about therapeutic substitution as it solely doesn't imply any judgement on efficacy or relative efficacy of drugs and group of drugs. ${ }^{15}$

Average number of drugs per prescription was found to be 9.42 , which is akin to study conducted by Nagabhushan $\mathrm{H}$ et al, $(7.8 \pm 2.2)$ which shows polypharmacy, though they were prescribed for cardiovascular emergency. ${ }^{5}$ Polypharmacy is an area of concern for elderly patients since they are more prone to ADRs, thus cautious and insightful drug prescription strategy is by all accounts ready to dispose the vast majority of the cases of polypharmacy. $87.4 \%$ of drugs prescribed were from Essential Drug list (EDL) 2016-2018. ${ }^{16} 97.23 \%$ of drugs prescribed were from national list of essential medicines (NLEM) 2015 which is the reason why there was a very good positive outcome among therapy in patients during the treatment period. ${ }^{17}$

Sample size used in this study was very small (150) and also the duration of study was short (4 months). Results of this study cannot be extrapolated to general population since study was single centred (i.e. it was carried out in a single government hospital). If other regional hospitals had been included in the study better results would have been generated.

\section{CONCLUSION}

In this study authors found that drugs were prescribed rationally and accordance to current guidelines being practiced. Majority of the drugs were prescribed in generic form, therefore cost benefit for the patients. 
Polypharmacy could be supervised in elderly patients by following certain criteria's like Beers criteria and STOPP/START criteria, Unnecessary drug use by the patient should be identified by the health care team appointed and stopped. Moreover, tools like ARMOR (Assess, Review, Minimize, Optimize, Reassess) would be useful to evaluate polypharmacy in elderly patients.

Appointing competent clinical pharmacist at all tertiary care hospital setups could further add to the effectiveness in treatment and outcome both directly and indirectly.

\section{ACKNOWLEDGEMENTS}

Authors would like to thank Associate professor, physicians and staff; Department of General Medicine.

\section{Funding: No funding sources}

Conflict of interest: None declared

Ethical approval: The study was approved by the Institutional Ethics Committee

\section{REFERENCES}

1. WHO, about cardiovascular diseases. Available at: http://www.who.int>about_cvd.

2. Planton J, Edlund BJ. Strategies for reducing polypharmacy in older adults. J Gerontol Nurs. 2010 Jan 1;36(1):8-12.

3. Tripathi KD. Cardiovascular diseases: Textbook of Essentials of Medical Pharmacology. $8^{\text {th }}$ Ed. New Delhi: Jaypee Brother Medical Publication;2019:524604.

4. Kerkar SS, Bhandare PN. Study of utilization trends of drugs in patients admitted with cardiovascular diseases at a tertiary care hospital in Goa. Int J Sci Rep. 2017 Dec;3(12):311-7.

5. Nagabushan H, Roopadevi HS, Prakash GM, Pankaja R. A prospective study of drug utilization pattern in cardiac intensive care unit at a tertiary care teaching hospital. Int J Basic Clin Pharmacol. 2015;4(3):57983.

6. Pendhari SR, Chaudhari DR, Burute SR, Bite BM. A study on the drug utilization trends in the cardiovascular emergencies in a tertiary care hospital. J Clin Diagnos Res. 2013 Apr;7(4):666-70.

7. Vakade KP, Thorat VM, Khanwelkar CC, Jadhav SA, Sanghishetti VM, Veeramachaneni R, et al. A study of prescribing pattern of drugs in patients of cardiovascular emergencies at a tertiary care hospital of Western Maharashtra. Int J Res Med Sci. 2016 Feb;4(2):556-61.

8. Nooreen M, Maryam, Hani H, Fatima S, Sania H, Habeeb A, et al. A pharmacoepidemiological study of cardiovascular drugs in ICCU patients in a tertiary care hospital. Int J Med Res Health Sci. 2018;7(4):88-93.

9. Arnett DK, Blumenthal RS, Albert MA, Michos ED, Buroker AB, Miedema MD, et al. 2019 ACC/AHA Guideline on the Primary Prevention of Cardiovascular Disease. J Am Coll Cardiol. 2019:1101.

10. Lavanya S, Joel GO, Aswathy S, Anju A, Jintu MM, Sandra MS, et al. A prospective study of drug utilization pattern of cardiac inotropes in cardiac intensive care unit at a tertiary care hospital. Drug Invent Today. 2018;10(2):244-7.

11. Chandana N, Subash V, Kumar V. A prospective study on drug utilization of cardiac unit in acute myocardial infarction of hospitalised patients. Int J Pharmacother. 2013;3(1):6-11.

12. Aswani R, Reddy PK, Yanadaiah P, Sujatha S. A study on prescribing pattern of cardiovascular drugs and potential drug-drug interactions in an inpatient cardiology unit of a cardiac-care hospital at Tirupathi. Eur J Pharmaceut Med Res. 2016;3(8):294-305.

13. ATC/DDD Index 2019, WHO collaborating centre for drug statistics methodology. Available at: whocc.no/atc_ddd_index.

14. Hannan A, Sinha S, Jamadar P. Drug utilisation study of cardiac emergency patients in a tertiary care hospital. J Evol Med Dental Sci. 2017 Apr 3;6(27):2217-25.

15. WHO. How to investigate drug use in health facilities: selected drug use indicators-EDM Research series No.007(WHO/DAP/93.1). 1993;3:28-30. Available at: https://www.who.int/medicines/publications/howto-investigate_drug-use/en/.

16. Essential drug list (EDL) for the year 2016-2018. Available at: http://www.nrhmhp.gov.in/sites/default/files/files/Lis t\%20of\%20EDL(2).pdf.Accessed 30 March 2019.

17. National List of essential medicines 2015- CDSCO. Available at: http://cdsco.nic.in/writereaddata/nlem2015/nlem,\%202015.pdf.

Cite this article as: Fardan M, Manjari S, Periasamy S. Study of drug utilization in cardiovascular emergency at a rural teaching hospital in Tamilnadu, India. Int J Basic Clin Pharmacol 2019;8:1587-93. 